the insertion of a cannula open at the end could not fail to give rise? An artificial point appeared to be the only solution; and it seemed to me that cocoa-butter was possessed of a peculiar fitness for the purpose ; for this reason; for 2 hard dense substance, its dissolubility under moderate heat is, I believe, quite without parallel. Subjection to a temperature of $96 \mathrm{degs}$. dissolves such a portion of it as my purpose requires with curious rapidity -in as nearly as possible one minute. There is besides the additional advantage that it serves as a lubricator in its passage to the bladder. But it is not in connection with my instrument alone that this application of it will, I hope, be found to be a profitable discovery, but in every operation where it is expedient tem. porarily to close the mouth of a catheter or cannula. I mean that I consider the cocoa-butter point per se worthy of attention.

I would now briefly suggest to you a further adaptation of the principle and form of the Extractor that may be found useful. As a selfretaining catheter (Fig 3), I cannot help thinking it would prove as simple and effective an appliance as could be used; and I know that the increased demand for these instruments of late has called forth various improvements and emendations in the means both of introduction and of retention.

After speaking so long of myself and my own labours, it is especially pleasant to me to turn from them to the more agreeable task of acknow ledging, which I will do as briefly as possible, the obligations that I am under to those who have generously afforded me assistance, which has been invaluable to me in surmounting the difficulties with which I have had to contend.

Amongst my medical friends I must mention Mr. Barnard Holt, to whom I am indebted for sound practical advice. To Dr. Robert John Lee I owe more than I can express, for the unwearying patience and kindne ss with which he has assisted me in my experiments on the dead subject; also to Mr. Warrington Haward of St. George's Hospital, who deserves my warmest thanks not only for facilities and personal help afforded me in the post mortim room, but for the preparation now on the table, by which I hope to be able to exemplify practically the processes I have described.

The success that has attended the manufacture of the instruments is due in part to the care and at tention bestowed on them by Mr. Charles Maw, of the firm of Maw and Son, Aldersgate Street ; and in part to Mr. Jaques, the representative of the firm of Messrs. IVarne and Co., Tottenham India-rubber Works, who, in the cause of science and su $\mathrm{f}$ fering humanity, spared neither time nor trouble in bringing to perfection the India-rubber tube and convolvulus, devoting his best energie; to the work in hand, with unflagging interest, until the end was accom. plished.

The Calculus Detectors which I have brought with me this evening, were made by Mr. Hawksley of Blenheim Strcet, who has taken especial pains to carry out my instructions.

For assistance in procuring suitable chemical agents for the solutions I have alluded to, my best thanks are due to $\mathrm{Mr}$. Gale, of the firm of Bell and Co., Oxford Street, and to Dr. Flite, of the British Miseum.

It remains only to commend the inventions to your criticism, and, if they meet with approval, to your adoption. That they are faultless, it would be too much to hope. Time and use would doubtless suggest improvements, modifications, and additions; but if the principles be sound, a step will have been gained. It would have been more satisfac. tory for you, and certainly for me, had I been able to bring evidence of successful operations effected by their means; perhaps on a future occasion some of the gentlemen present may be able to supply this omi-sion. Meantime, I am content to hand them over to the profession-for what they are worth.

\section{NOTES ON CONSUMPTION.}

By RICIIARD PAYNE COTTON, M.D., F.R.C.P., Senior Physician to the Hospital for Consumption and Diseases of the Chest, Brompton; ctc.

\section{IV.-Consumption AND H.emoptysis.}

SOME years ago, there was an interesting discussion at the Medical Society of London, respecting the significancy of hremoptysis; and I quite well remember the general impression at that time, that phrhisis and hæmoptysis were so essentially related to each other as to justify the conclusion that they were but different terms for expressing the some condition. It was, in fact, simply but significantly put by one of the speakers, and received the general assent of the meeting, that " "himoptysis meant phthisis." Those who, like myself, were in the habit of seeing a vast number of consumptive patients at a special chest-hospital, might very fairly have joined in such a conclusion, the two conditions being in such institutions constantly associated. A further reflection upon this point, however, must make it sufficiently obvious, that the value of hrmoptysis, in a diagnostic point of view, cannot be exclusively studied in consumptive patients, but that the expectoration of blood must be taken as a separate condition or symptom which must be traced backwards to its cause or origin.

My own opinion may be thus briefly stated. I consider that phthisis must claim hamoptysis as one of its most frequent and important symptoms ; but that expectoration of blood is very often indeed quite unconnected with tubercular disease.

I propose, in the first place, to consider hxmoptysis in its nontubercular relations.

r. Any cardiac obstruction, whether from excessive or diminished action of the heart, or from any defect in its valvular structures, may produce hæmoptysis, which may be either small or large in amount, and either pure or mixed with hronchial secretion. Perhaps the most common and severe cases of hemoptysis from heart-disease occur in con. nection with mitral obstruction ; but cardiac derangement of any kind, by disturbing the normal balance of the pulmonary circulation, is liable to be attended with this symptom. What was formerly known as "pulmonary apoplexy," and which is generally due to heart-obstruction, is often attended and relieved by the occurrence of hamoptysis.

2. Hamoptysis from the rupture of an aneurism of the general circu. lation is occasionally met with ; but it is, of course, usually to a large and rapidly fatal amount; although the final rupture is sometimes preceded by small and occasional discharges of blood, arising either from local pressure or the conyestion of surrounding parts.

3. Hxmoptysis is an occasional but far from common attendant upon intrathoracic malignant growtls; but in such casis it is usually small in amo int.

4. Simple bronchitis, whether acute or clironic, sometimes, hut not often, gives rise to hxinop'ysic. I remember two such cases in which the loss of blood was extreme, and in one of them nearly fatal; but the more common form of bronchial hemop'ysis is of molerate quantity, and is evidenced rather by tinged or streaky sputa than by pure or abundant blood.

5. Bronchial congestion, or that state of lung short of actual pneu. monia, is often attended, and indeed relieved by, more or less hamoptysis. Such condition is frequently to be met with in low febrile states, in which the pulmonary orgaus have become implicated.

6 True pneumonia, as is well known, is a constant occasion of hemoptysis; but in this disease the blond is selilom pure, but intermixed with pulmonary secretion in the wcll known form of "rust-coloured" expectoration. Pneumonia, which has passed into a cluronic form, is also of en attended with hromoptysis.

7. Hamoptysis is occasionally met with in connexion with an im. poverished or thinned condition of the blood, the bleeding not being limited to the pulmunary or bronchial membranes, but proceeding also from the throat or gums or other parts. In one such case which fell under my notice, there was likewise a sanguineous exurtarion from several parts of the body, and even from the exiremities of the fingers. In this form of bleeding, which has sometimes been called spurious hxmoptysis, but which is nevertheless a reasonahle source of alarm. and may occasion doubtfulness even to the medical mind, the blowd is never pure, but of a thin watery churacter, much resembling. as I have else. where described it (On Hacinotysis, Lancet, vol. 2, 186j), a mixture of red currant jelly and water.

8. Not infrequently a congested state of the pharyngeal mucous membrane or of the tonsils is attended with an excape of b!oun, eirher pure or mixed with mucus from the surrounding parts. I have frequently seen this occasion great anxiety, as it is often arsociated with a defective state of the general health, which may easily be construed into consump. tive sumptoms.

9. Many writers have treated of a form of hæemoptysis which they have styled "vicarious." as being either supplementary to, or tak in: the place of other discharges, but especially the calamenia. I do not deny the possible existence of such cases, but I confess that I have urver met with what have been to me satisfactory in-tances of the kind. Hamoptvsis must, of course, sometimes be coincilent with the catamenial or other discharges of blood; hut I have never met with an unequivocal intance of the one superseding, or being interchangtable with, the other.

From these few observations, briefly bit perhaps sufficiently put, it will, I think, be apparent that in pracice, we must meet will many cases of blood expecrorarion, which are quite unconnecter with consumption, and that the ifea once prevalenr, and which I think to some extent still remains, that hremoptysis is practically but another name for phthisis, must be erroneous.

I have next to consider hæmoptysis in its bearing upon phthisis. [To be continued.] 